\title{
Emoticons as a Non-Verbal Communication Cue in the CMC Environment
}

\section{$\mathrm{CMC}$ 환경에서의 \\ 비언어적 의사소통 수단으로서의 이모티콘}

Hyewon $\operatorname{Lim}^{1}$

임혜원 ${ }^{1}$

${ }^{1}$ Professor, College of Kedang General Education, Sangmyung University, South Korea, hyewonlim@smu.ac.kr

\begin{abstract}
The purpose of this study is to investigate the roles, functions, and motives of using emoticons in addition to verbal messages in non-face-to-face, Computer-Mediated Communication such as SNS, instant messenger. In a face-to-face communication situation, non-verbal elements of the speakers such as facial expression, gestures, postures are as important as verbal utterances in grasping the speaker's intentions and meanings of conversation. Likewise, in a non-face-to-face, CMC environment, the use of emoticons is essential to convey subtle messages such as emotions and attitudes that is hard to grasp via verbal communication. Such active use of emoticons is related to a strong motivation for communication of the users even in a very limited environment. It was found that the CMC participants are using emoticons in negative situations to mitigate the face-threatening messages and/or to reduce conflicts in human relationships. Emoticons are also used to perform various speech acts such as 'agree', 'disagree', 'compliment', 'blame', 'congratulate', 'apologize', and 'console', through which they serve the function of maintaining the relationship by expanding positive reactions and reducing negative reactions of the other speakers. It can be said that emoticons perform the function of a politeness strategy to show deference and reduce the loss of face of conversation participants. Researches on emoticons from the perspective of linguistics and communication theories have been rare until recently. Just as gestures play a major role in face-to-face communication, emoticons need to be discussed as essential elements in non-verbal communication.
\end{abstract}

Keywords: CMC(Computer-Mediated Communication), Emoticon, Non-Verbal communication, Speech Acts

요약: 이 연구는 SNS 채팅, 메신저와 같은 비대면 컴퓨터 매개 의사소통(CMC) 상황에서 이모 티콘을 사용하는 동기를 살피는 데 목적이 있다. 대면 의사소통 상황에서 얼굴 표정, 몸짓, 자세와 같은 비언어적인 요소는 발화자의 의도와 대화의 의미를 파악하는 데 있어서 매우 중 요한 비중을 차지한다. 비대면 의사소통 상황에서도 대화 참여자들은 문자언어로 나타낸 정 보 외에도 감정이나 태도와 같은 메시지를 전달하기 위한 도구를 필요로 하는데, 그 대표적 인 예가 이모티콘이다. SNS 이용자들은 여러 종류의 이모티콘을 구입해서 사용할 정도로 비 대면 대화 속에서 이모티콘을 적극적으로 사용한다. 이모티콘 사용은 의사소통을 통해 충족 시키고자 하는 사용자의 욕구와 관련이 있다. 사용자들은 자신의 감정을 표현하기 위해 이모

Received: June 03, 2021; ${ }^{\text {st }}$ Review Result: July 21, 2021; $2^{\text {nd }}$ Review Result: September 04, 2021 Accepted: October 31, 2021 
티콘을 사용하는 것은 물론 자신의 의사를 드러내는 과정에서 상대방의 체면을 덜 손상시키 고 인간관계에서 갈등을 줄일 목적으로도 이모티콘을 사용한다. 이모티콘은 동의, 반대, 칭 찬, 비난, 축하, 사과, 위로 등의 대화행위를 수행하고 있는데 이것을 통해 상대에게 긍정적 인 반응은 강화하고 부정적인 반응은 약화시킴으로써 대화 분위기를 부드럽게 만들고 원만한 인간관계를 유지하도록 만들어준다. 따라서 이모티콘은 대화 참여자들의 체면 손상을 줄이고 상대방을 대우하는 공손 전략 기능을 수행한다고 할 수 있다. 이처럼 이모티콘은 비대면 대 화 상황에서 의사소통 기능을 하는 비언어적 요소로서 분석되고 논의되어야 할 필요가 있다.

핵심어: 이모티콘, 비언어적 의사소통, 대화행위, 컴퓨터매개의사소통(CMC)

\section{1. 서론}

우리나라 인터넷 이용자 비율은 2020년 기준 91.9\%에 달하며[1] 한국 성인 스마트폰 사용률은 2017년 이후 93\% 수준을 유지하고 있다[2]. 이와 같은 기술의 발전과 함께 발달한 디지털 문화, SNS 문화의 영향으로 이제는 직접 만나지 않고도 서로의 소식을 주고받으며 대화를 나누는 것이 일상에서 매우 자연스러운 일이 되었다. 최근 코로나 바이러스 감염증 19(COVID 19) 유행을 계기로 디지털 환경에서의 컴퓨터 매개 의사소통의 비중이 높아졌으며, 비대면이라는 특성이 가지고 있는 장점 때문에 이와 같은 의사소통 방식은 앞으로 더욱 활성화될 것으로 보인다.

컴퓨터 매개 의사소통(Computer-Mediated Communication: 이하 CMC)이란 네트워크 플랫폼을 통한 사람들의 의사소통 방식을 뜻한다. $\mathrm{CMC}$ 환경에서는 문자로만 표현해야 하기 때문에 사람들은 대면 의사소통 상황에서 유용했던 비언어적인 요소를 대체하기 위한 방법들을 모색해 왔다[3]. 최근의 연구들은 이와 같은 CMC 환경에서 새롭게 발견되는 비언어 및 준언어적 신호들을 온라인 언어의 일부이자 의사소통의 필수 요소로 보고 있다[4]. 이모티콘은 표정이나 행동을 그림으로 나타낸 것으로, 비대면 대화 상황에서 표현상의 한계를 극복하기 위한 수단으로 고안되었다고 할 수 있다. 이모티콘이 활발하게 사용된다는 것은 문자 중심의 환경에서 이미지 중심의 환경으로 전환되고 있음을 보여주며, 이모티콘은 앞으로 문자언어를 대체하고 감성언어로서의 역할까지 담당하게 될 것으로 전망된다[5]. 이 연구에서는 $\mathrm{CMC}$ 환경에서의 이모티콘의 역할을 의사소통 관점에서 살펴보고자 하였다.

\section{2. 이모티콘 연구 현황}

이모티콘(emoticon)은 감정(emotion)과 도상(icon)이 합쳐진 말로, 초기에는 컴퓨터 자판에 있는 문자를 조합하여 사람의 눈, 코, 입으로 보이게 만들어서 표정을 보여 주려던 것에서 시작되었다. 이러한 이모티콘을 텍스트 이모티콘이라고 하는데, 이렇게 문자의 배열만으로 기쁨, 슬픔, 당황 같은 기본 감정을 표현하는 방식으로 사용되다가 온라인 환경이 점차 확장되면서 이미지가 담긴 그래픽 형태로 발전되고, 나아가 움직임까지 포함된 애니메이션 이모티콘으로까지 발전되어 다양한 감정과 태도, 분위기를 표현할 수 있게 되었다. 사람들은 좋아하는 캐릭터로 이루어진 이모티콘이나 자신이 표현하고 싶은 정서를 담은 이모티콘을 구매해 가면서까지 사용하고 있다. 
이모티콘 시장의 규모는 3,000 억원에서 5,000 억원 규모로 추산되는데 이러한 사실만 보아도 사람들이 이모티콘을 얼마나 많이 사용하고 있는가를 알 수 있다.

이모티콘은 사용자의 요구에 맞는 방향으로 발전되어 왔다. 이것은 의사소통을 통해 충족시키고자 하는 사용자의 욕구와 관련이 있다. 이모티콘은 카카오톡 등 SNS 의사소통에 있어서 중심적인 역할을 하고 있는데, 비대면 대화 상황에서 주로 비언어적인 부분을 담당하고 있다. 앨버트 메라비언(A. Mehrabian)은 저서 <비언어적 의사소통(Nonverbal Communication(1972)>에서 의사소통에서 음성언어의 비중을 단 $7 \%$ 로 보고 손짓, 몸짓, 자세, 어조와 같은 요소의 비중을 $93 \%$ 라고 함으로써 의사소통에서 비언어가 차지하는 비중을 가장 높게 평가한 연구자이다. 언어표현을 통해 구체적으로 전달되는 정보성이 중요한 경우를 제외하고는 비언어적인 요소가 의사소통에서 차지하는 비중이 높다는 데는 학자들 간에 이견이 없다.

사람들은 대면하지 않은 상황에서도 상호작용적 몸짓(interactive gestures)을 사용한다. 손을 움직이지 말고 말을 하라는 요구를 받은 사람이 단지 손만 쓰지 말라고 했을 뿐인데도 말을 하는 것 자체를 불편해했다는 실험 결과도 있는 것을 보면 사람들은 몸짓을 사용해야 말을 더 잘 할 수 있다고 생각하는 것 같기도 하다[6]. 비언어적인 요소는 상대방의 감정이나 태도 등 현재 상황을 판단할 수 있는 단서가 된다. 의사소통의 주체인 우리는 텍스트를 중심으로 한 비대면 의사소통 상황에서도 이러한 역할을 담당해 줄 도구가 필요하다고 생각한다. 문자언어로만 전달되었을 때 생길 수 있는 감정적 오해를 줄이고 효과적으로 의사소통할 수 있도록 만들어주는 또 다른 요소가 있어야 하는 것이다. 이모티콘은 이와 같은 사람들의 의사소통 욕구를 충족 시켜 줄 수 있는 가장 좋은 도구이며, 비대면 상황에서 자신을 효과적으로 드러낼 방법이 되기도 한다. 이러한 점 때문에 이모티콘을 유사언어(paralanguage)로 본 연구자도 있다[7].

이모티콘 사용 양상에 대한 선행 연구는 주로 디자인, 언론정보, 경영학 분야에서 이루어졌다. 연구자들은 이모티콘을 사용하는 동기를 감정 표현, 의사소통 활성화, 사회적 관계의 형성, 문화적 정체성 형성[8], 이미지 관리, 문장 보완[9], 그리고 놀이[10] 등으로 보았다. 모바일 메신저를 이용하고 있는 전국 만 19세 59세 남녀 1,000 명을 대상으로 실시한 이모티콘 사용에 대한 조사에서도 전체 사용자의 $81.3 \%$ 가 친밀감 표현을 이모티콘을 사용하는 주된 동기로 꼽았다[11]. 이러한 연구 결과들은 텍스트만으로는 건조한 $\mathrm{CMC}$ 환경에서 이모티콘 사용이 분위기를 쉽게 화기애애하게 만들고 대화 참여자들 간의 친밀감을 높여 상호작용을 촉진시킬 수 있는 방법이 될 수 있다는 것을 보여준다.

이모티콘의 사용 양상은 연령과 개인적 성향에 따라서도 다르다. 20 대는 자신의 상황을 구체적으로 묘사하는 행동 표현 이모티콘을 선호하며 장년층은 의미가 명확하고 간결한 이모티콘을 선호하는 경향이 있다고 한다[12]. 한편, 예방 초점 성향이 강한 사람은 자신의 감정을 우회적으로 전달하기 위해 이모티콘을 사용하며, 향상 초점 성향이 강한 사람은 자신의 감정을 정확하게 전달할 목적으로 이모티콘을 사용한다고 한다[13]. 이 밖에도 이모티콘을 의사소통 참여자들의 감정과 의지가 담긴 함축적 기호로 다룬 연구[14], 가상성과 익명성을 바탕으로 한 개인의 또 다른정체적 자아표현으로 다룬 연구도 있다[15]. 이모티콘은 비대면 의사소통 상황에서 자신의 의도와 성향을 드러내는 수단임이 분명해 보인다. 


\section{3. 비언어적 의사소통 수단으로서의 이모티콘}

비언어적 의사소통(non-verbal communication)이란 언어 이외의 다른 방식으로 이루어지는 의사소통을 일컫는 말로, 환경, 참여자의 외형, 신체 움직임과 위치 등을 통한 정보 전달을 의미한다[16]. 의사소통 상황에서 일반적으로 음성언어는 지식 정보를 전달하고 비언어적인 요소는 감정적 정보를 전달하는 것으로 보고 있다. 카카오톡과 같은 SNS 의사소통에서는 문자언어는 지식 정보를 전달하며 나머지 정보는 모두 이모티콘이 전달한다고 볼 수 있다. 카카오톡 대화는 문자언어로 이루어지지만 구어의 속도를 추구하기 때문에 문자 입력을 통한 속도의 차이를 극복하기 위해 음절을 축약하는 것과 같은 방법이 동원되기도 한다[17]. 이모티콘을 선택하여 입력하며 사용하는 것은 대화 속도를 늦추는 일이기도 하겠지만 카카오톡 이용자들은 기꺼이 이 불편을 감수하며 심지어 비용을 지불하면서까지 이모티콘을 적극적으로 사용한다. 대학생 70 명을 대상으로 실시한 이모티콘 사용에 관한 기초 조사에서 이모티콘을 사용하는 가장 큰 동기는 감정 표현과 관계 표현으로 나타났다. 이 조사는 카카오톡에서 제공하는 기본 이모티콘 48 개 가운데 선호하는 이모티콘을 최대 다섯 개를 고르고 그것들을 사용하는 이유를 주관식으로 적도록 하는 방식으로 진행하였다. 그 결과는 다음과 같다.

[표 1] 이모티콘 사용 동기

[Table 1] Motivation for Using Emoticons

\begin{tabular}{|c|c|c|c|}
\hline 사용 동기 & 답변 내용 & \multicolumn{2}{|c|}{ 빈도 } \\
\hline 감정 표현 & $\begin{array}{c}\text { 기쁨, 슬픔, 부끄러움, 화, 재미있음/없음, 피곤함, 애정, 당황, } \\
\text { 짜증, 놀람, 지루함, 머쓱함 }\end{array}$ & 101 & \\
\hline $\begin{array}{l}\text { 관계 표현 } \\
\text { (대화행위) }\end{array}$ & $\begin{array}{l}\text { 감사, 동의, 축하, 부탁, 기대, 응원, 칭찬, 사과, 인사, 확인, } \\
\text { 위로, 자랑, 환영, 대답, 대답 요구, 수락, 거절, 장난 }\end{array}$ & 181 & 323 \\
\hline 기타 & $\begin{array}{c}\text { 태도(잘난 척, 모르는 척), 사태(망함), 텍스트만 쓰기 허전해서, } \\
\text { 딱히 할 말이 없을 때, 행위(먹기, 자기) }\end{array}$ & 41 & \\
\hline
\end{tabular}

[표 1]을 통해 우리는 감정을 표현하기 위해 이모티콘을 사용할 뿐만 아니라 감사, 동의, 축하 등의 대화행위임을 드러내기 위해 이모티콘을 자주 사용하고 있음을 알 수 있다. 따라서 이 연구에서는 감정 표현과 관계 표현을 중심으로 이모티콘의 표현 방식에 대해 살펴보고자 하였다.

\section{1 감정 표현}

찰스 다윈(C. Darwin)은 <인간과 동물의 감정 표현(The Expression of the Emotions in Man and Animals, 1872)>에서 인간과 동물은 표정과 몸짓을 통해 자신의 감정과 심리 상태를 본능적으로 드러낸다고 하였다. 비언어적 의사소통을 연구한 학자들은 선천적으로 시각 장애가 있어 다른 사람의 감정 표현을 본 적 없는 사람들도, 감정에 대한 단어를 가지고 있지 않은 민족도 모두 같은 방식의 감정 표현을 한다고 하였다. 감정 표현은 정보 전달과 함께 의사소통을 통해 추구하고자 하는 가장 중요한 목적이다. 대면 의사소통 상황에서는 표정과 몸짓 같은 비언어적 신호를 통해 감정 표현이 이루어지지만, 문자언어 중심의 $\mathrm{CMC}$ 환경에서는 감정 정보를 전달하는 기능을 이모티콘이 담당하고 있다. 문자언어는 사실 상대방이 그것을 어떤 느낌으로 읽게 될지 
모른다는 점에서 불완전한 소통 방법이다. 내 의도와 다른 어조로 문자언어를 읽을 수 있다는 위험 부담이 있으며 종종 그러한 일로 인한 오해와 갈등이 일어난다는 것을 알고 있다. 그렇기 때문에 번거롭더라도 자신에게 구비되어 있는 이모티콘들 가운데 자신의 발화 의도에 가장 잘 들어맞는 감정이 표현된 이모티콘을 골라서 보여주는 방식의 의사소통 방법을 사용하는 것이다.

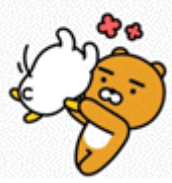

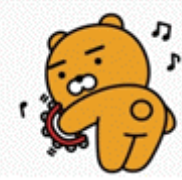

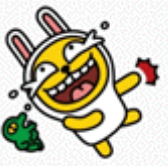

[그림 1] 기쁨과 즐거움

[Fig. 1] Joy \& Happiness
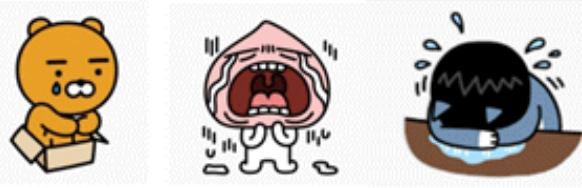

[그림 2] 슬픔

[Fig. 2] Sadness

[그림 1]은 기쁨과 즐거움을 표현하는 애니메이션 이모티콘으로 타인의 손을 잡고 빙글빙글 돌거나 춤을 추거나 벽을 치면서 크게 웃는 것과 같은 큰 동작으로 형상화되어 있다. 눈을 크게 만들어 보이는 것으로도 기쁨을 표현할 수 있는데 이것은 좋은 감정일 때 동공이 확장되는 신체적 경험에 근거한 표현 방식이라고 할 수 있다. 이와 같은 이모티콘을 사용하게 되면 '정말 좋아요.' 라고 말하는 것과 같은 효과를 거둘 수 있어 의사소통 상황에서는 동의한다는 의미를 전달할 수 있다. [그림 2]는 슬픔을 표현하는 이모티콘 사례로 정도는 다르지만 모두 눈물을 흘리는 모습으로 표현되어 있다. '목놓아 울다' 와 같은 언어표현이 있는 것처럼 슬픔을 억제하지 않고 모든 것을 내려놓고 오열하는 모습의 이모티콘도 있으며, 자신이 흘린 눈물에 몸이 잠기는 것과 같은 이모티콘도 있다. 몸을 작게 만들어 상자 속에 몸을 넣는 모습으로 슬픔을 표현한 것도 흥미로운데, 기쁨을 나타내는 이모티콘의 동작이 큰 것과는 대조적인 모습이다. 이와 관련하여 인지언어학적으로 몸짓을 연구한 학자들이 [기쁨은 위, 슬픔은 아래]와 같은 개념화(conceptualization) 방식에 근거한 보편적으로 유형화된 동작언어 방식이 있다고 한 바 있다.
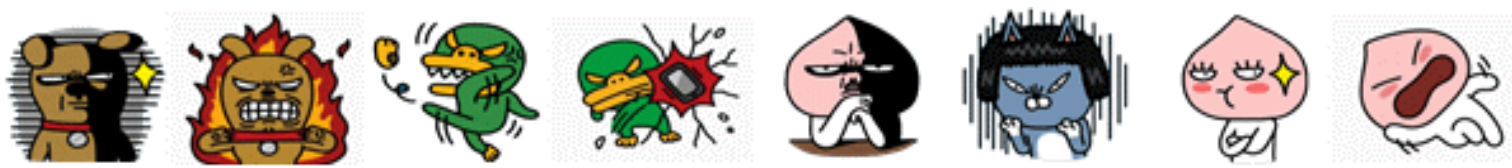

[그림 3] 분노와 혐오

[Fig. 3] Anger \& Disgust

[그림 3]은 분노와 혐오를 표현하는 이모티콘으로, 눈매가 뾰족하게 위로 올라가고 낯빛이 어두워지거나 불길이 치솟거나 무엇인가를 걷어차고 던지고 몸부림을 치는 것과 같은 과격한 동작으로 분노와 혐오 감정을 보여주고 있다. [그림 3]에서 오리 같이 생긴 캐릭터는 다른 감정일 때는 흰색인데 화가 났을 때만 녹색으로 변하는데,

'붉으락푸르락하다' 라는 언어표현이 있는 것처럼 피부색의 변화를 통해 분노를 보여주는 방식으로 캐릭터가 고안된 점이 흥미롭다. 분노를 드러내는 이모티콘의 모습들은 실제로 화가 나면 심박 수가 증가하고 체온이 상승하게 되는 신체적 경험에 
근거하여 디자인되었다고 할 수 있다. 또한 동공이 아주 작거나 없는 것으로 표현되어 있는데 이것은 실제로 분노, 혐오, 두려움 등 좋지 않은 감정일 때 동공이 축소되는 것과 같은 신체적 반응과 관련이 있다. 카카오톡에서 이와 같은 이모티콘을 사용하게 되면 '나 지금 화가 났다' 는 의미뿐만 아니라 불만을 의미하여 거절과 거부의 의사 표현을 대신에 할 수 있다. 이와 같은 의사 표현은 3.2 에서 다룰 대화행위 기능과도 관련되어 있다. 이모티콘은 동물 등 사람이 아닌 캐릭터의 모습을 한 경우도 많다. 동물에 사람 모습이 투사되었을 때 웃음이 유발되는 효과가 있어서[18] 슬픔이나 분노 같은 부정적 정서를 전달한다고 하더라도 이모티콘은 대화 분위기를 무겁지 않게 만드는 기능을 한다. 이모티콘의 이러한 기능과 효과 때문에 사람들은 재미있고 귀여운 캐릭터로 이루어진 이모티콘을 선호한다[19].

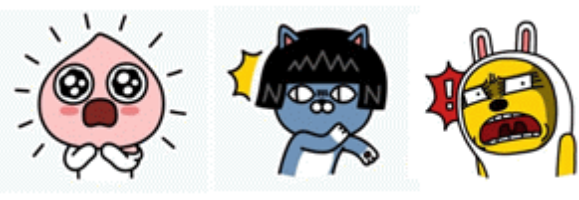

[그림 4] 놀람

[Fig. 4] Surprise

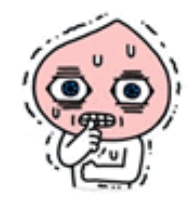

[그림 5] 두려움

[Fig. 5] Fear

놀람을 나타내는 이모티콘에는 [그림 4]에서처럼 모두 캐릭터의 머리 부분에서 빛이 번쩍하는 것과 같은 모양의 그림이 포함되어 있다. 우리가 깜짝 놀라게 되면 근육이 갑자기 수축했다가 이내 이완되는데 빛이 번쩍 하는 그림은 바로 이러한 놀람의 순간성을 표현한 것이라고 할 수 있다. 긍정적인 이유에서도 놀릴 수 있고 부정적인 이유에서도 놀랄 수 있는데, 동공이 커지면서 놀라는 모습은 긍정적 느낌을 주고 동공이 작고 낮빛이 어두워지면서 놀라는 모습은 부정적인 느낌을 준다. 이모티콘 사용자들은 상대방이 선택한 이모티콘의 표정과 동작을 통해 상대방의 의도에 가깝게 대화의 의미를 해석할 수 있게 된다. 두려운 감정이 들면 체온이 내려가고 몸이 떨리게 되는데, [그림 5]는 이와 같은 신체적 반응을 반영하고 있는 이모티콘이다. 이 밖에도 [그림 6]과 같이 부끄러운 감정이나 정확하게 표현하기 어려운 불편한 심정을 드러내는 이모티콘들도 많이 있다.
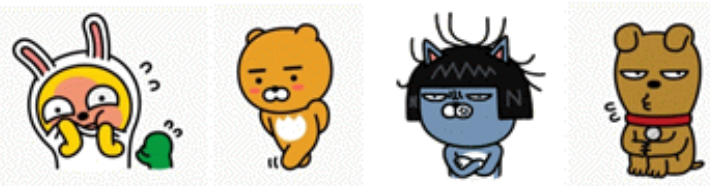

[그림 6] 그 밖의 감정

[Fig. 6] Other Emotions

이모티콘을 사용한다는 것은 지금 말을 하고 있는 자신의 현재의 느낌과 감정을 가장 직접적으로 표현한 것이라고 볼 수 있는데 이렇게 사용된 이모티콘은 상대방으로 하여금 문자언어를 해석하기 위한 맥락(context)으로 작용한다. 텍스트만으로는 의도를 파악하기 어려울 때 이모티콘이 맥락 정보로 사용되는 것이다. 이처럼 이모티콘에는 정서를 포함한 인간의 경험 방식과 관련하여 많은 정보를 담고 있으며, 더 다양하고 
복합적인 감정과 분위기, 상황을 반영하는 방향으로 이모티콘 상품이 개발되고 있다.

\section{2 관계 표현}

이모티콘이 감정 표현 기능에 치중되어 있을 것 같지만, 기초 조사 결과인 [표 1]에서도 보았듯이 실제 이모티콘의 사용 양상을 살펴보면 감정 표현 외에도 인사, 축하, 대답, 사과, 기대, 위로 등의 대화행위(화행, speech act) 표현들이 높은 빈도로 사용되고 있다. 말은 단순히 담고 있는 의미만을 전달하는 것이 아니라 말하는 것 자체가 행동일 수 있고 그 말로 인해 타인의 행동을 유발하기도 한다. 따라서 대화행위는 대화 참여자들 간의 상호작용이라고 볼 수 있다. 대화행위를 통해 대화 참여자들 사이의 관계를 형성하고 대화 종료 이후에도 또다른 행위가 이루어짐으로써 관계가 지속되도록 만들기도 한다. 카카오톡과 같은 비대면 대화 속에서는 이모티콘이 대화행위 기능을 하고 있으며 대화 참여자들 사이에서 우호적인 관계를 유지하기 위한 수단으로 사용된다.
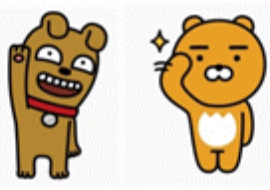

[그림 7] 인사

[Fig. 7] Greetings
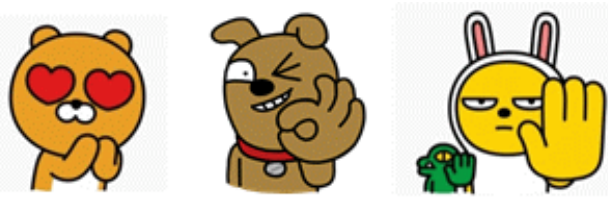

[그림 8] 동의와 반대

[Fig. 8] Agreeing \& Disagreeinh

이모티콘은 대화 시작과 종결 부분에서 더 자주 사용되는 경향이 있다. [그림 7]에 제시한 이모티콘은 손을 흔들거나 경례를 하는 동작을 하는 이모티콘으로 “안녕하세요?" 또는 “안녕히 계세요.” 와 같은 언어표현에 대응된다. [그림 7]의 오른쪽 이모티콘은 “네, 알겠습니다.” 와 같은 의미로도 사용된다. 또한 '좋다' 는 의미를 전달하기 위해 [그림 8]과 같은 이모티콘을 사용하면 긍정적인 느낌을 강화할 수 있다. 이때 “싫어요." 와 같은 문자언어 대신 또는 문자언어와 함께 손바닥을 내밀어 거부하는 이모티콘을 사용하면 사용자의 대화 성향에 따라 부정적인 느낌을 감소시킬 수 있다. 우리는 의사소통에서 상대의 제안이나 요구에 대해 거절을 하게 되면 거절을 하는 사람도 거절을 당하는 사람도 체면손상(face threatening)을 경험하게 되는데 이모티콘 캐릭터가 가지고 있는 귀여움과 유머 효과 때문에 거절에 대한 부정적 정서를 감소시키는 효과를 거둘 수 있다. 이모티콘이 대화에서 일종의 애교 기능을 담당하고 있다고 할 수 있는데, 부정적인 대화행위를 할 때 이모티콘을 사용하게 되면 상대방의 체면을 덜 손상시키고 관계가 악화되는 것을 막는다. 이러한 점에서 이모티콘은 비대면 의사소통 상황에서 공손 전략(politeness strategy) 수단이 될 수 있다. 따라서 이모티콘은 의사소통 참여자들 사이의 관계를 유지시키기 위한 의사소통 기제라고 볼 수 있다. 텍스트 이모티콘의 기능을 다루었던 한 연구에서 지도, 명령, 비지지, 불인정, 주제 전환에 해당하는 메시지는 상대와의 관계에서 언제나 우위를 점하려고 하는 관계 통제 시도가 이루어지는데 이때 이모티콘 사용은 상대에게 영향력을 행사하는 상황에서 친밀감을 표시하고 원만한 관계를 유지하기 위한 예절로 인식되게 함으로써 관계의 위협 가능성을 줄인다고 한 논의와도 일맥상통한다[20]. 

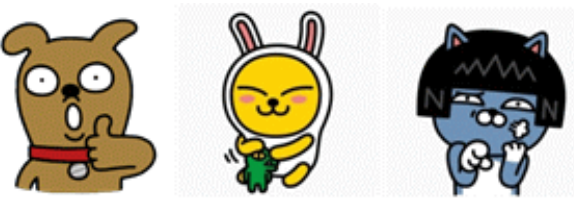

[그림 9] 칭찬과 비난

[Fig. 9] Complimenting \& Blaming

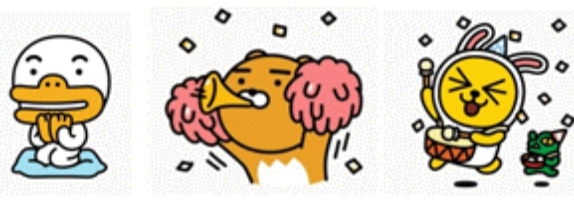

[그림 10] 축하

[Fig. 10] Congratulating

[그림 9]는 “최고입니다.” , “참 잘했어요.” 와 같은 칭찬의 대화행위와 “그렇게 하면 안 됩니다.” 와 같은 비난의 대화행위를 대신하고 있는 이모티콘이다. 비난도 상대방의 체면을 손상시키는 부정적인 대화행위이다. 상대에게 동의하거나 상대를 기분 좋게 해주는 대화행위는 관계를 돈독하게 만들기 때문에 대화 중에 여러 번 사용해도 부담이 없지만, 상대에게 반대 의사를 드러내거나 요구를 거절하거나 비난하는 대화행위는 상대의 기분을 상하게 하여 자칫 현재의 관계에 부정적인 영향을 끼칠 수도 있기 때문에 이와 같은 표현을 하는 것 자체가 매우 부담스럽다.

부정적인 의사 표현의 이모티콘은 캐릭터의 희화를 통해 의사소통 상황에서 부정적인 정서를 감소시키고 있는 것으로 보인다. 예를 들어, [그림 9]의 단발머리 고양이 캐릭터가 상대방을 가리키는 손짓과 콧김을 내뿜는 행위를 함으로써 비웃는 모습을 보여주고 있는데 대면 대화 상황에서 대화 참여자가 실제로 그와 같은 행위를 한다면 이것을 본 상대방은 매우 불쾌할 수 있지만 재미있게 생긴 캐릭터가 그와 같은 행위를 하면 심각하게만 해석할 필요는 없다는 생각하게 될 것이다. 감정 표현을 드러내는 이모티콘 중에서도 분노나 슬픔 같은 감정 표현에 대해 눈물과 콧물이 흘러내려 바닥이 흥건해지게 한다든가 상대방을 향해 휴대전화를 집어 던지고 신발이 날아갈 정도로 세게 걷어차는 행위를 하는 등 더욱 과장된 행위로 표현된 것도 부정적인 감정이나 부정적인 의사 표현을 하는 것에 대한 부담감을 캐릭터가 가지고 있는 유머를 통해 감소시킬 수 있기 때문으로 보인다. 물론 비난 대화행위나 감정을 지나치게 과격하게 표현한 이모티콘의 사용을 조심스러워하는 사용자도 있다.

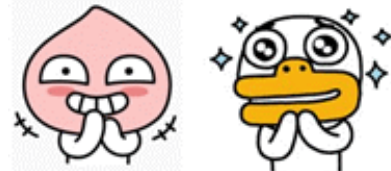

[그림 11] 기대

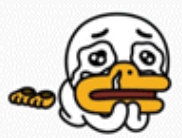

[그림 12] 사과와 위로

[Fig. 12] Apology \& Consolodation
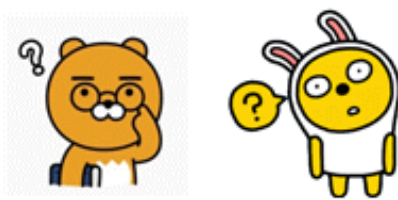

[그림 13] 의문

[Fig. 11] Hope

[Fig. 13] Doubt

[그림 11]은 상대방에게 무엇인가 바라는 것이 있을 때 사용하는 이모티콘이다. 두 손을 모아 기대감을 표현하고 있으며 선택하는 이모티콘 캐릭터의 표정에 따라 다른 의도가 있는 기대 또는 간절한 열망을 구분해서 표현할 수 있다. [그림 12]의 엎드려 두 손을 모아 비는 행위를 하는 이모티콘은 사과의 의미를, 눈물을 흘리며 누군가를 토닥이는 행위를 하는 이모티콘은 공감과 위로의 의미를 전달하고 있다. [그림 13]의 안경을 쓰거나 고개를 갸웃거리며 물음표를 제시한 이모티콘은 지금의 상황이 의문스러우니 답변이나 해명을 요구하는 대화행위를 대신한다. 모두 상대방에게 또다른 
행위를 요구하는 것으로서 상대방에게 부담을 주는 체면손상행위를 하는 것이라고 볼 수 있다. 이와 같이 이모티콘은 의사소통 상황에서 대화행위 기능을 수행하되 상대방의 체면을 덜 손상하면서 우호적인 관계를 지속시킬 수 있도록 하는 기능을 하고 있다고 볼 수 있다.

이모티콘은 비대면 대화 상황에서 일종의 간접대화행위와 같은 기능을 하는 것으로 보인다. 이모티콘은 정보 중심 대화보다는 친교 중심 대화에서 주로 쓰인다. 정보를 전달할 목적이라면 다양한 해석의 여지가 적은 언어표현을 사용하겠지만, 친목을 다지기 위한 대화에서는 순서교대(turn taking)를 통해 대화를 이어나가고 좋은 대화 분위기를 유지시키는 것이 중요하다. 이모티콘은 그림이기 때문에 감정 정보는 제공하지만, 구체적인 메시지 기능은 상대적으로 약하다. 따라서 이모티콘은 자신이 전달하고자 하는 의도를 직접적으로 드러내지 않는다는 점에서 명확한 의미가 있는 언어표현보다 유용할 수 있다. 이모티콘은 여러 가지로 해석할 수 있는 여지를 주는 방법이 되기도 하므로 대화와 관계를 유연하게 만들 수 있는 기능도 한다. 언어적인 답변 대신 감정을 드러내는 이모티콘을 사용하면 긍정적인 정서는 증폭시키고 부정적인 정서는 감소시킬 수 있다. 앞에서 들었던 예로, 문자언어로 “싫어." 라고 쓰는 것보다 토끼 캐릭터가 손바닥을 내미는 이모티콘을 사용하면 거절에 대한 거부감을 줄일 수 있어서 거절하는 자신도 보호하고 상대의 체면도 지켜줄 방법이 되는 것이다. 이모티콘이 직접적 표현에 의한 이해보다 간접적 표현에 의한 다양한 해석의 가능성을 열어두고 이미지를 투영하거나 함축하는 과정을 통해 주관적으로 이해하게 만드는 수단이 될 수도 있기 때문이다[13]. 또한 대화 참여자들은 화자의 사회적 영향력을 약화시켜서 의사소통 목표를 달성하는 과정에서도 이모티콘을 사용하기도 하는데, 이모티콘이 공격적인 언어표현에 의해 발생하는 적대감을 완화하거나 긍정적으로 해석할 수 있게 만들기 때문이다.

의사소통 상황에서 언어표현과 함께 사용한 표정이나 몸짓은 언어표현의 의미를 이해하는 데 도움을 주기도 하지만, 어떤 경우에는 언어표현과 함께 사용한 표정이나 손짓 때문에 언어표현과는 다른 의미를 전달하기도 한다. 마찬가지로 언어적 메시지와 함께 사용한 이모티콘은 언어적 메시지의 의미를 보조하기도 하고, 때로는 함께 사용한 이모티콘 때문에 언어적 메시지와는 다른 의미를 전달하기도 한다. 이러한 점 때문에 비언어적인 표현이 상대방의 감정이나 태도를 파악하고 인간관계를 유지하는 데 있어서 언어적인 것보다 의사소통에서 기여하는 바가 더 크다고 보게 되는 것이다. 따라서 비대면 의사소통 상황에서의 이모티콘의 사용은 의사소통 주체의 이와 같은 다소 복합적인 의사소통 욕구를 만족시키기 위한 것으로 볼 수 있다.

\section{4. 결론}

지금까지 카카오톡과 같은 비대면 의사소통 상황에서 비언어적 의사소통 수단으로서의 이모티콘의 사용 동기에 대해 살펴보았다. 이모티콘을 사용하는 가장 큰 의사소통의 동기는 문자언어 중심으로 이루어지는 의사소통 상황에서 발화자의 감정과 태도를 표현하고 원만한 인간관계를 이어나가기 위한 것으로 보인다. 카카오톡과 같은 비대면 의사소통 상황에서도 문자언어로 나타낸 메시지 외에 감정이나 태도, 분위기를 표현하기 위해 이모티콘 사용이 필요한다는 것이다. 비언어 의사소통 연구자들은 비언어라는 것을 구어(spoken)와 문어(written)를 초월하는 의사소통 현상을 기술하는 개념으로 보고 
있는데[16] 이것은 의사소통에서 비언어 신호와 언어 신호를 따로 떼어놓고 말할 수 없다는 것을 의미한다.

이모티콘 사용의 일차적인 동기는 감정 표현이 분명해 보인다. 다양한 종류의 이모티콘은 기쁨, 슬픔, 분노, 혐오, 놀람, 두려움과 같은 기본 감정을 포함하여 복잡하고 미묘한 감정들을 표현하기 위해 특화되어 있다. 이모티콘 사용의 또 다른 중요한 동기는 관계 유지 기능으로, 이모티콘은 동의, 반대, 칭찬, 비난, 축하, 사과, 위로 등의 대화행위를 수행하고 있는데 이것을 통해 상대에게 긍정적인 반응은 확대하고 부정적인 반응은 감소시킴으로써 대화 종료 후에도 우호적인 관계를 유지하도록 하는 기능이 있다. 또한 그림으로 이루어진 이모티콘은 언어적 메시지만큼 명시적인 정보성은 없기 때문에 상대방으로 하여금 다양한 해석을 유발하는 일종의 간접대화행위 기능을 한다. 여기에 이모티콘이 가지고 있는 귀여움과 유머 효과 때문에 대화를 즐겁게 만들기도 한다. 따라서 자신의 의사를 드러내는 과정에서 상대방의 체면을 덜 손상시키고 인간관계에서의 갈등을 줄이기 위해서도 이모티콘을 사용한다고 할 수 있다.

이 연구는 이모티콘을 비대면 대화 상황에서의 비언어적인 의사소통 요소로서 분석될 수 있는 가능성을 살핀 연구라고 할 수 있다. 카카오톡과 같은 실제 대화 자료를 수집하여 문자언어와 이모티콘의 사용 양상을 함께 분석하게 되면 이모티콘의 기능과 역할에 대해 보다 심층적이고 구체적인 논의가 가능할 것으로 보인다. 또한 다양한 이모티콘을 선택하여 사용하는 이유와 의사소통 효과를 검증하기 위한 실증적인 조사 연구를 통해 이모티콘의 의사소통적 관점에서의 논의를 발전시켜야 할 것으로 생각된다.

\section{References}

[1] 2020 Internet Use Servey, Ministry of Science and ICT, (2020)

[2] 2020 Gallup Survey: Smartphone, Smart Watch, Wireness Earphone, Korea Gallup, (2020)

[3] N. Liebman, D. Gergle, It's (Not) Simply a Matter of Time: The Relationship Between CMC Cues and Interpersonal Affinity, In Proceedings of the 19th ACM Conference on Computer-Supported Cooperative Work \& Social Computing, pp.570-581, (2016), February 27; California, USA.

[4] I. Vandergriff, Emotive communication online: A contextual analysis of computer-mediated communication (CMC) cues, Journal of Pragmatics, (2013), Vol.51, pp.1-12, DOI: https://doi.org/10.1016/j.pragma.2013.02.008

[5] Young-mi Lee, A Study on the Characteristics of Visual Communication of Social Network Service by Expression Type, Journal of Basic Design \& Art, (2012), Vol.13, No.4, pp.255-265, UCI: G704-001069.2012.13.4.007

[6] Hyewon Lim, A study of SCALE schema conceptualization through verbal/nonverbal utterance analysis, Discourse and Cognition, (2021), Vol.28, No.2, pp.169-193, DOI: 10.15718/discog.2021.28.2.169

[7] P. A. Thompson, D. A. Foulger, Effects of pictographs and quoting on flaming in electronic mail, Computers in Human Behavior, (1996), Vol.12, No.2, pp.225-243, DOI: 10.1016/0747-5632(96)00004-0

[8] Kyoo-Lak Cho, Yeon-Jeong Ji, The Differences of Emoticon Use and its Effects Depending upon Problem Types and Discussion Message Types in the Process of Online Problem-Solving Discussions, Journal of Educational Technology (2016), Vol 32, No.2, pp.355-390, DOI: 10.17232/KSET.32.2.355

[9] Eunji Lee, Motivations for the Using Emoticon : Exploring the effect of Motivations and Intimacies between Users on the Attitude and Behaviors of Using Emoticon, Jourmal of the HCI Society of Korea, (2017), Vol.12. No.2, pp5-12.

[10] Jong Yoon Lee, A Study on Motivation and Satisfaction of using KakaoTalk Emoticons, Journal of Basic Design \& Art, (2018), Vol.19, No.1, pp.435-446, DOI: 10.47294/KSBDA.19.1.33 
[11] Mobile Sticker(Emoticon) Tracking Survey, Embrain, Trend Monitor, (2014)

[12] Hye Kyung Lee, Eun Young Koh, A Comparative Study on Characteristics of Those in Their Twenties and Elderly Citizens in Using Instant Messenger Emoticons - Centering on Kakao Talk Emoticons -, A Journal of Brand Design Association of Korea, (2015), Vol.13, No.2, pp.145-156, DOI: 10.18852/bdak.2015.13.2.145

[13] Bong-Goon Seo, Do-Hyung Park, Motivation of Emoticon Usage in Online Messenger Service: Focusing on Regulatory Focus, Knowledge Management Review, (2020), Vol.21, No.2, pp.101-118, DOI: 10.15813/kmr.2020.21.2.006

[14] Jang Sun Hong, Jong Yoon Lee, A Study on kakaoTalk Emoticons through Self-Representation and Symbol Characteristic, Journal of Basic Design \& Art, (2014), Vol.15, No.4, pp.493-505, UCI: G704-001069.2014.15.4.026

[15] Jang Sun Hong, A Study on Non-verbal Communication through Self-Representation and Symbol Characteristic: Focus on SNS Emoticons, Korean Journal of Communication Studies, (2016), Vol.24, No.3, pp.5-31, UCI: G704001501.2016.24.3.002

[16] M. L. Knapp, J. A. Hall, T. G. Horgan, Nonverbal Communication in Human Interaction (8th Edition), Cengage Learning, (2013)

[17] Myung-won Choi, Sun-young Kim, Ji-hye Kim, Ae-kyoung Lee, A study of Linguistic phenomena of SNS Messenger Kakao Talk, Textlinguistics, (2012), Vol.33, pp.469-495, DOI: 10.22832/txtlng.2012.33..016

[18] Eunkoung Lee, Myoungsik Choi, Cheeyong Kim, Study on Laughter-arousing Factors of Character Designs of Kakaotalk Emoticons, Journal of Korea Multimedia Society, (2015), Vol.18, No.2, pp.253-259, DOI: $10.9717 / \mathrm{kmms} .2015 .18 .2 .253$

[19] Subin Kim, Joonghwan Hwang, Cohesion Analysis of Empathy Preference According to KakaoTalk Emoticon Category, The Journal of Humanities and Social science, (2020), Vol.11, No.5, pp.1175-1189, DOI: 10.22143/HSS21.11.5.85

[20] Hyunkoo Park, Relationship between Emoticons and Nonverbal Behaviors in Online Chatting System: Emoticons as Relational Control Mechanism, Journal of Communication Science, (2005), Vol.5, No.3, pp.273-302, UCI: G704001590.2005.5.3.008 